\title{
Latin American Center Symposium on Environment and Health: Exploring Natural Products
}

\section{April 19, 2005, Moss Auditorium, Room A2-342 Marion Davies Children's Clinic (MDCC) Center For Health Sciences}

\author{
Edwin L. Cooper ${ }^{1}$ and Susanna B. Hecht ${ }^{2}$ \\ ${ }^{1}$ Laboratory of Comparative Neuroimmunology, Department of Neurobiology, David Geffen School of Medicine \\ at UCLA, University of California, Los Angeles, CA 90095-1763, USA and ${ }^{2}$ UCLA School of Public Affairs, \\ 5270 Public Policy Building, Los Angeles, CA 90095-1656, USA
}

This will be an interdisciplinary one-day symposium that should be of great interest to biologists, especially botanists, biomedical researchers, practitioners of complementary and alternative medicine, and public health workers. What do the forests in Venezuela and Brazil and plants from California yield as natural products that can be exploited as alternative therapies for the benefit of health? The popular press (e.g. every Monday, the LA Times health section gives an example of some kind of 'cure') is a good source of information. Thus there is an ever-growing awareness of the possibility of using such natural products in place of other drugs. Most important, there is an attempt to place these products within the realm of solid science through the publication of evidence-based reports. The symposium will be organized around three international experts who will give formal presentations from 9:00 to 12:00 h. After a no-host two-hour lunch, we will reconvene from 14:00 to $17: 00 \mathrm{~h}$ for a roundtable discussion. There is no charge for participation and everyone is welcome.

\section{The Systemic Theory of Living Systems and Relevance to CAM Part I: The Theory}

José A. Olalde Rangel

Adaptogenic Educational Medical Centers and Venezuelan Association of Systemic Medicine, Caracas, Venezuela

'The Systemic Theory of Living Systems' is being published in several parts in $e C A M$. The theory is axiomatic. It originates from the phenomenological idea that physiological health is based on three factors: integrity of its structure or

For reprints and all correspondence: Edwin L. Cooper, Distinguished Professor and Editor-in-Chief, eCAM. Email: cooper@mednet.ucla.edu organization, $O$, functional organic energy reserve, $E$, and level of active biological intelligence, $I$. From the theory is derived a treatment strategy called systemic medicine (SM). This is based on identifying and prescribing phytomedicines and/or other medications that strengthen each factor. Energystimulating phytomedicines increase available energy and decrease total entropy of an open biological system by providing negative entropy. The same occurs with phytomedicines that act as biological intelligence modulators. They should be used as the first line of treatment in all ailments, since all pathologies, by definition, imply a higher than normal organic entropy. SM postulates that the state of health, $H$, of an individual is effectively equal to the product of the strength of each factor $H=O \times E \times I$. SM observes that when all three factors are brought back to ideal levels, patients begin the recovery to normal health. The systemic solution is definitely environmental since it is also epidemiological. If we enhance epidemiology, we make better our environment.

\section{Ethnopharmacology as Source of New Drug Paradigms: Examples from Amazonian Traditional Medicines and Implications for Developing Innovative Psychoactive Drugs}

\section{Elaine Elisabetsky}

Laboratório de Etnofarmacologia, Departamento de Farmacologia, ICBS, Universidade Federal do Rio Grande do Sul, Porto Alegre, RS, Brazil

The pharmaceutical industry regards medicinal plants as potential sources of unusual bioactive molecules that potentially bear innovative mechanisms of action. For allopathic drug development, even when traditional formulations

(C) The Author (2005). Published by Oxford University Press. All rights reserved.

The online version of this article has been published under an open access model. Users are entitled to use, reproduce, disseminate, or display the open access version of this article for non-commercial purposes provided that: the original authorship is properly and fully attributed; the Journal and Oxford University Press are attributed as the original place of publication with the correct citation details given; if an article is subsequently reproduced or disseminated not in its entirety but only in part or as a derivative work this must be clearly indicated. For commercial re-use, please contact journals.permissions@oupjournals.org 
are taken into consideration, traditional medical systems are very rarely regarded in the same way. The herbal industry is more likely to accommodate innovations and to accept unconventional concepts of health/disease, maintenance/ treatment and drug mode of action, thereby eventually generating useful clinical data. Despite its history, pharmacology as a discipline has been refractory to the potential contribution of ethnopharmacology in terms of different paradigms for drug mode of action or usage. The complex patterns frequently found in pharmacological studies of medicinal plant extracts suggest that the effects of plant drugs may often be based on a more diverse or complex pharmacodynamic basis than the common drug-effect relationships. In fact, pharmacological properties and clinical effects observed with herbal drugs may result from effects of more than one active ingredient, from drug interactions among ingredients, from active ingredients possessing multiple mechanisms of action or even from interference with targets not yet recognized by the current biomedical understanding of cell biology modulation. This presentation focuses on the psychopharmacological profiles of a variety of traditional Amazonian medicines to explore newer paradigms of psychotropic drug action and therapy. It is suggested that the understanding of traditional medical concepts of health and disease in general, and traditional medical practices in particular, can lead to true innovation in paradigms of drug usage and drug development.

\section{Chumash Healing}

James D. Adams $\mathrm{Jr}^{1}$ and Cecilia Garcia ${ }^{2}$

${ }^{1}$ Department of Molecular Pharmacy and Toxicology, University of Southern California, 1985 Zonal Avenue, PSC 508, Los Angeles CA, USA and ${ }^{2}$ Granada Hills, CA, USA

Chumash healing begins with prayer. The spirit must be healed first. When the spirit is well, the body can be healed. Plants can be used to heal the spirit and the body. The authors will discuss white sage, black sage, chia, mugwort, California sagebrush, yerba santa, California jimson weed, California tobacco, California bay and perhaps other plants. White sage is a spirit plant that should be used every day to soothe and calm the spirit and the body. Black sage can be used against pain. Chia can be used to restore strength. Mugwort should be used to promote dreaming and sleep. It can also be used at menopause. California sagebrush can bring back pleasant memories. Yerba santa should be used against breathing problems, colds, flu and other respiratory problems. California jimson weed can be used to protect the spirit. It can be used to help people adjust to the stages of life. California tobacco is used to consecrate prayers. It is also used to decrease hunger. California bay can be used against pain and even against migraine headaches. The authors will discuss techniques to keep the spirit and the body healthy, thereby preventing disease. 


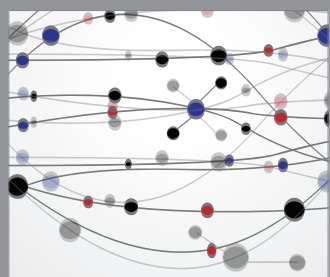

The Scientific World Journal
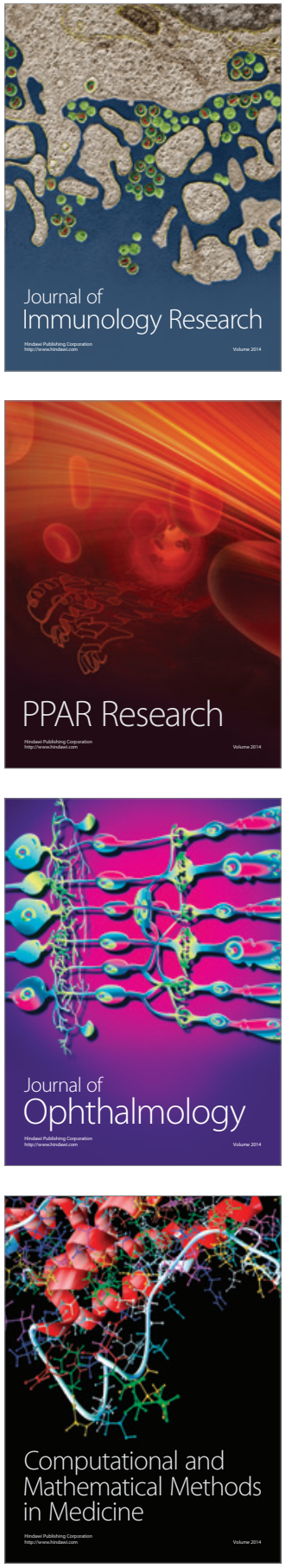

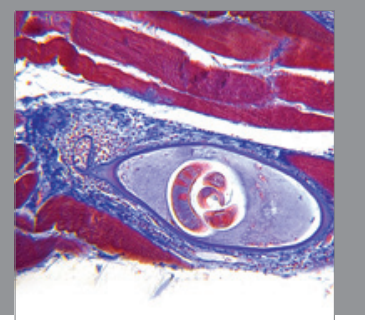

Gastroenterology

Research and Practice
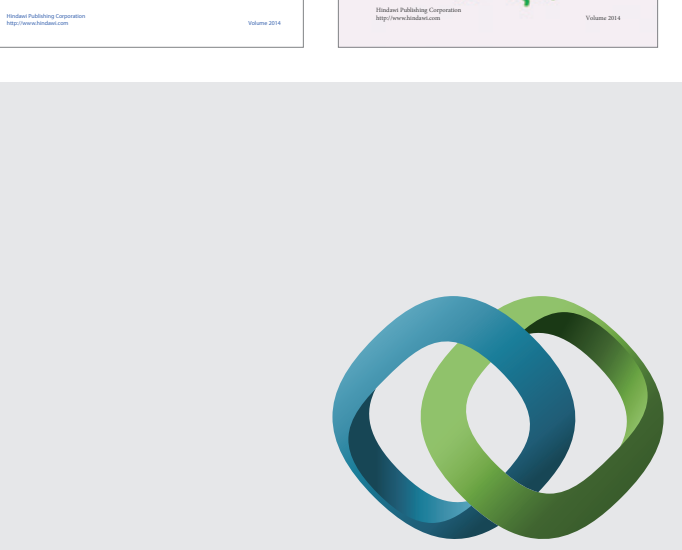

\section{Hindawi}

Submit your manuscripts at

http://www.hindawi.com
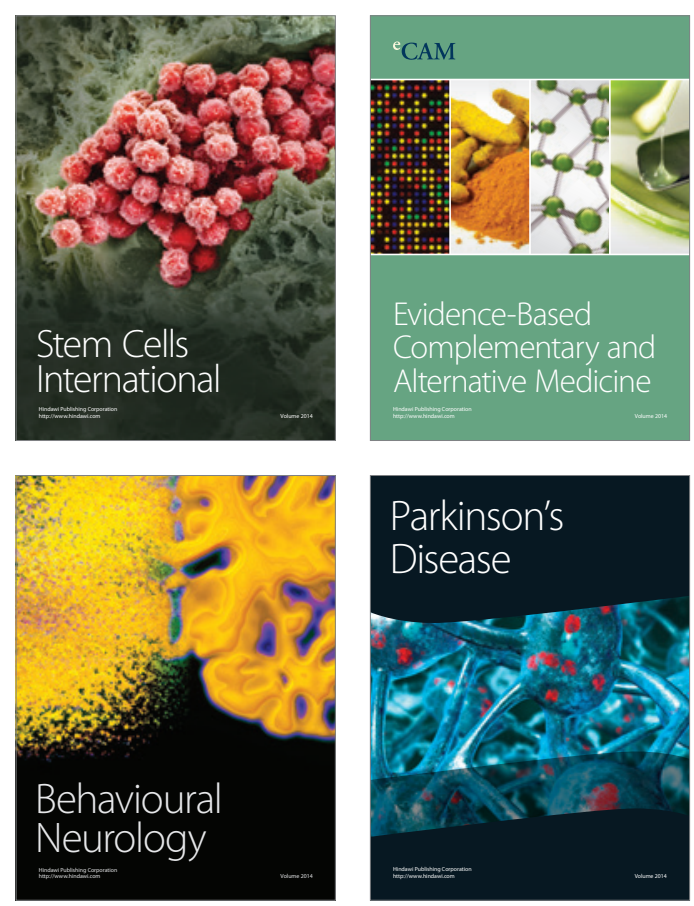

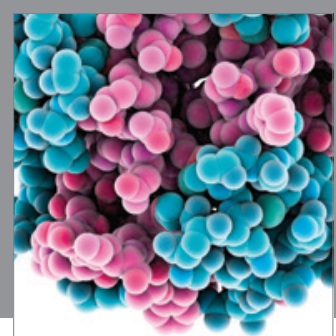

Journal of
Diabetes Research

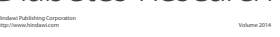

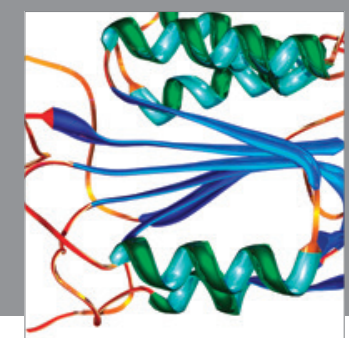

Disease Markers
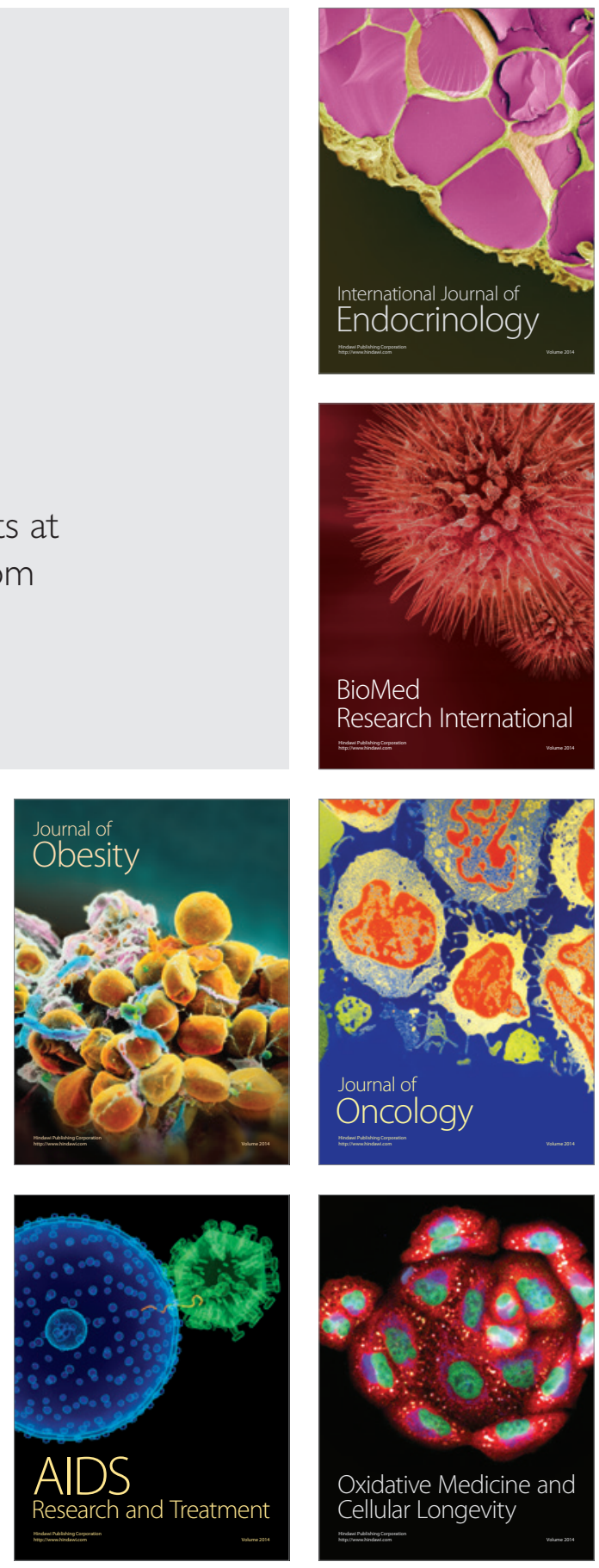